(REVIEW ARTICLE)

\title{
Behavior and attitude of the mobile phones users towards SMS advertising: A study in an emerging economy
}

\author{
Razzaq Abdul * and Ashfaq Muhammad \\ Faculty of management and Economics, Kunming University of Science and Technology, PR, China.
}

Publication history: Received on 03 November 2019; revised on 19 November 2019; accepted on 21 November 2019

Article DOI: https://doi.org/10.30574/wjarr.2019.4.1.0082

\begin{abstract}
Advertisement through SMS is a commonly used medium in the era of technology. Companies are utilizing this medium of advertisement quite frequently. Rapid increase of the usage of mobile phone has developed an innovative way of utilizing this marketing tools. Due to the exponential growth in telecommunication industry after introduction of SMS and MMS, this study has conducted to investigate the consumer attitude towards SMS advertisement and its relationship with behavior. Entertainments, irritation, product involvement and appeal were used in order to investigate attitude of the consumer. A questionnaire was used to examine the relationship among variables of the study. Overall 350 useable responses were gathered. SEM was used to obtain the results of the overall model. Result of the study indicates that 1 product involvement, appeal and entertainment have a positive impact on attitude towards advertisement. Only irritation was found to be negatively insignificant. (2) Relationship between consumer attitude towards SMS advertising and attitude was positively significant. (3) Positive and direct relationship between attitude and consumer behavior was also found. (4) Permission appeared to be significant on consumer attitude towards mobile advertisement, which confirmed that prior permissions required to gain the positive response of the consumer. (5) Consumer are attracted by rewards therefore monetary benefits was also found to be significant factor.
\end{abstract}

Keywords: Consumer; Advertisement; Utilizing; Frequently; Significant

\section{Introduction}

In the recent years, drastic advancement in mobile phone technology have changed the way of sharing, accessing and creating information [1]. The remarkable growth of the mobile phones use has highlighted the end of addressing consumers through SMS advertising [2]. In a survey conducted in Europe, it was found that 36\% of the marketers had been using MMS In a survey conducted in Europe, it was found that $36 \%$ of the marketers had been using SMS advertising for more than a year and within the six to twelve weeks, additional 39\% also started to use this media for advertising[3]. However ,this global trend is now estimated to reach $62 \%$ of the world spending report from marketer predicted that the expenditure on SMS and advertisement would reach 100 billion worldwide by spending report from 2016 (2015).

In the recent of technology, marketers have many mediums to communicate with their audience. However due to customization and personalization features of SMS advertising, marketers consider it a better way to reach the target audience. In the past marketers were limited to one- to -one medium of communication but outstanding advancement of technology has dramatically altered the way of traditional advertising which has resulted in new mediums of advertising for marketers [4].

The spending on worldwide SMS advertising was estimated $20.06 \%$ billion in 2015 [5]. High uses of mobile phones have created an enormous channel of advertising [6]. Digitalization also provides new means of mobile phone advertising.

\footnotetext{
${ }^{*}$ Corresponding author

E-mail address: razzaq1266@yahoo.com
} 
Digitalization also provides new means of mobile phone advertising. In order to attain maximum advantage, marketers should understand the aspect of uniqueness in order to attain [7]. Due to the consumer empowerment marketer need to understand the ups and downs of the SMS advertising medium as the behaviour of the consumer is not easy to predict [8].

Consumer, expectation increased and to ensure to transparency, marketers cannot rely only in one way of communication with their customers. After the emergence of the SMS advertising, it has been established that the sole reliance on traditional marketing is to appropriate to attain the same positive customer response which marketer used to obtain the in past. This has led to massive adoption of digital media in advertising campaigns [9]. Companies has realized the importance of interactive marketing and started using the new medium to interact. They send their promotional message to their customers' utilization the information regarding their demographic and geographic profiles. The purpose this study was to investigate consumer attitude towards SMS advertising as well as to check the relationship among consumer attitude, intention and their behaviour .It also aimed to investigate the impact of permission on consumer attitude towards SMS advertising and to analyse whether consumers prefer monetary benefits to receive SMS advertising

After the establishment of significance and popularity of SMS advertising, there is need to examine the following

- $\quad$ Factors that affect towards SMS advertising via appeal, entertainment irritation and product involvement.

- Impact of taking permission from consumers on their attitude towards SMS advertising.

- Impact of providing monetary benefits to consumers on their intention to receive SMS advertising.

\section{Uniqueness of SMS advertising}

Prior to analyzing the variables that influence attitudes towards SMS advertisement, it is essential to discuss the uniqueness of the SMS advertising in order to establish a frame work for literature review .SMS is consider to be a popular source of data service which is the most valuable and unique attribute of it [10]. Numerous studies in the past, done virtually and through telecommunication have empirically verified high effectiveness of spatial advertising. SMS marketing offers low cost advertising and new channel to generate revenue. It is also potential channel for consumers to enjoy relevancy of the content served to them at greater convenience.

Moreover, marketing mobile enables more result oriented customized message to ensure stronger relationship between customers and business [11].

Subscribers cannot avoid receiving SMS; at the least they are exposed to preview of the message before deciding to read it through or removing it. Forced exposure is said to have an interrupting effect on the usual viewing process of customers [12]. Additionally, customers exposed to such stimulus at the time display gauge able effect, like change of attitude. It can also potentially impact the acceptance of a SMS advertising.

\section{Factors affecting consumers attitude towards SMS advertising}

\subsection{Appeal}

Appeal drives people like to or act towards something. Appeal and benefit of SMS advertising have to subsections. Informative contents is related to the benefits and features of the product, which impact positively on the user's attitude [13]. Entertainment which is related to humorous contents and numerous types of the interactive games, enhance involvement and create a value in the mind of the customers. Emotional appeals are effective when there is low brand response. Comparatively, rational appeal is effective when customer are highly involved with brand and its advertisement. It has been proposed that utilitarian product, whereas value expressive products. It has been proposed that utilitarian appeals are effective for a utilitarian product [14].

Appeals are consider to be the most effective factors for SMS advertising. Product involvement, attitude towards SMS advertisement, incentives and advertising appeal have a direct impact on consumer attitude towards SMS advertisement, brand and purchase intention Contents and quizzes via SMS add value to advertising campaigns and they are effective in creating a positive attitude in the consumers towards SMS marketing. Entertainment and information are important factors for SMS advertising [15]. If advertisers and consumers enjoy a win -win situation, 
mobile marketing is expected to generate better result. If better advertisement based on the discussed literature, the first hypothesis is postulated.

*H1. There is significant impact of perceived appeal on consumer attitude towards SMS advertising.

\subsection{Entertainments}

Entertainment services are known to be build customers 'loyalty and do value addition for customers. When customers are offered prizes and games via short message, it increases their participation. Entertainment is important factors in next messages being well received and responded by the customers. Offering and prizes and involving cell phone users in interactive games is way to attract and retain customers. Entertainment also stimulates aesthetic enjoyment [16]. Enjoyment from an advertisement develops positive attitude of customers towards SMS marketing.

A message should contain elements of fun and entertainment to catch customers attention. These elements engage customers and make them familiar with services or product offering. The same strategy has been employed by Japanese mobile networks for promotion of internet to subscribers. The more entertaining the mobiles ads are, the higher the participation rate of customers. The option to add entertaining characteristics in mobile ads are numerous, such as puzzles jokes, ring tones, astrology and competitions explore more about this factor which shapes the attitude towards SMS advertising, the following hypothesis is proposed:

*H1. Entertainment has a significant impact on consumer attitude towards SMS advertising.

\subsection{Irritation}

The phenomenon of irritation explains negative reaction of customers to intrusive message. Customers perception of irritation from SMS ads has a negative relationship with their attitudes towards SMS advertisement [17]. It is believed that customers have a negative attitudes towards mobile advertisement and marketers need to adopt a cautious approach when employing SMS to gain potential customers attention, It is believed that customers have negative attitude towards mobile advertisement and marketers need to adopt a cautious approach when employing SMS to gain protentional customers' attention, especially the younger of target population [17].

The attitudes of model support relationship between customers' attitude towards advertisement and their perception of irritation from advertisements. Furthermore, it explains a negative correlation between the perception and attitudes of customers towards SMS ads. In this regard b, irritation is defined as the tactics that annoy, offend insult, or are overmanipulative. Advertisement designed and crafted by marketing experts, if sent to frequently, may be irritating for customers who have subscribed to such messages [18].

SMS advertisement may be confusing for customers when ads begin to distract customers by flooding them with information which may lead to negative reaction of customers towards advertisement. Unwanted messages known as SPAM, are another reason to annoy potential customer. SPAM violates customers 'privacy and may gather their personal formation, without proper permission. Incentives and rewards influence attitude and intention towards SMS advertisement. While credibility, irritation, informativeness and entertainment also have significant influence customers, attitude. In contrast, entertainment and informativeness influence consumer attitude more significantly as compared to irritation [19]. This leads to hypothesis proposed below: This leads to the hypothesis proposed below:

\section{*H3. Irritation has a significant impact on consumer attitude towards SMS advertising.}

\subsection{Product involvement}

Product involvement is defined as the commitment of customers towards brand or product type. Products vary by their nature of "think "or 'feel." Individuals purchase decisions are usually based on how they think or about product. An argument has been made by Laurent and Kapferer (1985) that product involvement is deciding factor for level of information given to customers and their active or passive response to advertisement. Product involvement influences the amount of motivation customers based on information provided in the advertisement. The higher the product involvement the higher is the likelihood for customers to process product-related information. Flow theory explains why people extend massive energy towards the activities of their own interest [20]. The theory describes flow to be the holistic sensation that people when they act with full involvement. The significance of factors related to SMS advertisement has been investigated in an experimental study. The study includes that product involvement, interactivity, advertisement appeal and attitude towards SMS advertising are general factors that affects attitude towards advertisement and attention of purchase. According to it, below is the suggested hypothesis: 
*H4: Product involvement has a significant impact on consumer attitude towards SMS advertising.

\subsection{Permission}

In relation with SMS advertisement, consumer permissions described as giving consent to receive SMS ads. Based on the previous theories, it is established that permission of users, wireless services providers control and brand trust primarily shape the users, acceptance of SMS advertisement [21]. A two-factor model message and media. The message refers to the content of message i.e. advertisement type such as competitions, polling, special offer s, message personalization and the time and frequency of an advertisement. The message also relates to location such as, location targeted offers, preferences of consumers, permission, consumer control and privacy. Privacy has been found to have the strongest negative impact on the attitude of consumer towards SMS advertisement. Furthermore, media factors consist of transmission, device media cost and product fit. A model was tested on the basis of the theory of reasoned Action. Which identified most important influences over the attitude of consumers towards SMS advertising. Also, the control of the end of the users over the frequency of advertisement messages and time affect the attitude of consumers.

A general positive behavior towards mobile advertisement of Iranian customers was witnessed, however they prefer to be contacted after prior. A significant positive impact of permission has been observed on the attitudes of end user SMS advertisement. This concludes that SMS advertisement $\mathrm{s}$ are consider to be valuable of prior permission has been granted from the receivers. The mobile advertising agencies enable consumers to opt in or out of the mobile ads [22].

The proposed model the study was empirically verified by succeeding researchers. A strong preference has been discovered for the network operators to function as media owners and hold permission to send SMS advertisement SMS advertisement. Obtaining permission of SMS advertisement is a fundamental aspect for SMS advertisement to be effective and successful. Rationally, receiving SMS advertisement from a trusted source has a higher chance of being accepted. Empirically, permission causes a positive and significant impact on the attitude of the end users and the attuite has been found to positively related to the intention of the end users to receive ads through SMS. Advertisement through SMS will be deemed valuable if they are sent after taking approval of the receiver [23].

As per the reviewed literature, the hypothesis is postulated as: $\mathrm{S}$

*H5. Permission-based advertising has a significant impact on consumer attitude towards advertising.

\subsection{Monetary Benefits}

Customers like to drive monetary rewards from marketing efforts targeted to them. A survey conducted in the United states found out $59 \%$ of the participants agreed to receive mobile ads if they are paid $\$ 1$. While around $66 \%$ of the participants agreed to receive mobile ads if they are rewarded. Monetary benefits for SMS advertisement refer to people agreeing to receive ads on their mobile phones for a promised or expected financial incentive [24]. This approach offers an attractive advantages of serving mobile users with a tangible reason to receive SMS advertising's offer the reward various means such as , coupons or mobile raffle can be used., which can be presented at a store or a shop for discount on purchase of services or products. Driving monetary rewards for direct marketing has been of interest for mobile users have effectively identified price discounts influencing buyers for product trial and purchase acceleration. Promotional efforts alter consumer purchase decision; hence retailers actively utilize this option to boost sales [25]. Positive attitude and purchase intention have also been positively correlated with incentives for mobile ads. A study has identified monetary benefits to be amongst the key factors that impact mobile advertisements. With reference to the studied literature, the following underlying hypothesis is suggested.

*H6. Monetary benefits have a significant impact on consumer intentions to receive SMS advertisements.

\subsection{Attitude and intention lead to consumer behavior}

After a thorough review of the literature on consumer behavior models and their attitude towards advertising, a framework of research has been ben construed to present the factors influencing the attitude of consumers towards SMS advertisement. The research framework also attempts to illustrate association among attitude, and actual behavior of the consumer towards SMS advertising. Theory of reasoned action (RTA) presented the three, attention and behavior, major constructs which are attitude, intention and behavior. The model constitutes the psychological process in relation with a person's beliefs, attitude and intention [26]. and explain the attitude and behavior. Permission is deemed to be a major element contributing to attitudes amongst three types SMS advertisement Monetary benefits such as, free talk time and SMS are also assumed to effective customers' attentions to accept mobile ads, followed by intention that influences the real behavior to receive the advertisement. Attitude can be defined as the extent of favorable or 
unfavorable response to given behavior. For instance, an individual with a positive attitude towards SMS ads. Contrary to this, an individual with a negative attitude will not have an intention to accept SMS ads [27]. It can be further explored with the help of the hypotheses postulated below.

*H7. Attitude towards SMS advertising has a significant impact on consumers' intention to receive SMS advertisement.

*H8. Consumer attention to receive SMS advertisement affect consumer behavior after receiving SMS advertisement.

\section{Empirical study}

The study has been carried out in Karachi, Pakistan in year 2015.An adapted questionnaire comprising three parts has been used to gather data for analysis.

The first part of the questionnaire which aimed to measure consumer attitude towards SMS advertising through appeal, entertainment, irritation and product involvement, was adopted from. The second part has questions related to the intention to receive SMS advertisement and the behavioural change after receiving SMS advertisement, adopted from [28]. Third part of the questionnaire is designed to get the demographic profile of the respondents. Figure 1 demonstrate the model of the study.

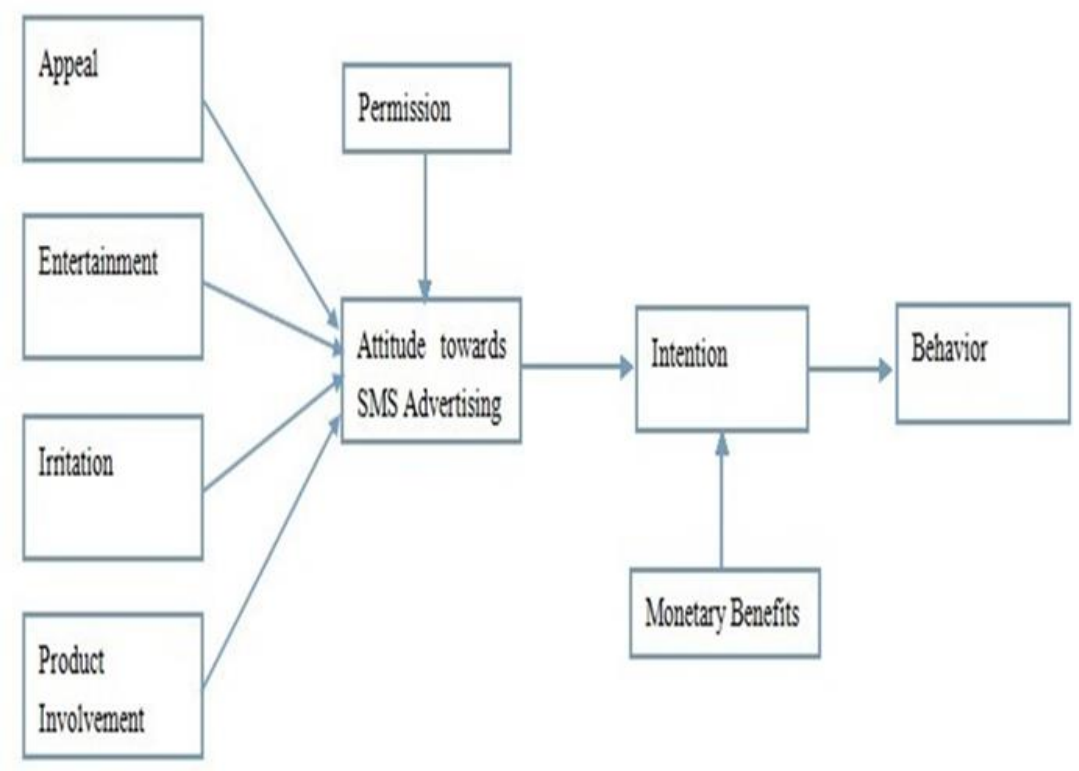

Figure 1 Model of the study

\section{Data analysis and finding}

\subsection{Data profile}

A total of 370 responses were gathered from the from the mobile phone users in which only 350 responses were unable able at the percentage rate of $94.6 \% .350$ questionnaires were distributed in person and 50 questionnaires were sent via email to collect online responses from potential respondent in five week survey from May,2015 to June ,2015.The useable responses consisted of male (226) and female (124) respondents with a percentage of $64.6 \%$ and $35.4 \%$ respectively. The age of the respondents ranged between 25 years to 50 years, while $55.1 \%$ of the respondents were from the age group 25 to 35 years. Most of the respondents were graduates (37.4\%) and postgraduates (37.4\%). The respondents with the monthly income of PKR 40,000 and above were $28.9 \%$ of the sample population. Table. 1 depicts descriptive profile of the respondents.

\subsection{Data analysis}

The data was initially tested for the reliability. The value of Cronbach's alpha represents the reliability of data which should be greater than 0.6. After ensuring enough reliability of the data which should be 0.05 . it was used for further 
analysis. Explorer factor analysis was employed by using varimax rotation with the help of SPSS22. Table 2 represents the overall factor loadings of the individual items. After making the constructs, confirmatory factor analysis was done by using Amos 22. Table 3 represents the CFA loading and reliability.

Table 1 Summary of Demographic Profile of the Data

\begin{tabular}{lll}
\hline $\begin{array}{c}\text { Gender } \\
\text { Percentage \% }\end{array}$ & Frequency \\
\hline Male & 226 & $65 . .6$ \\
Female & 124 & 35.4 \\
\hline Age & & \\
\hline $25-30$ & 193 & 55.1 \\
$31-35$ & 82 & 23.4 \\
$36-40$ & 31 & 8.9 \\
$40-45$ & 22 & 6.3 \\
$46-50$ & 22 & 6.3 \\
\hline Educational level & & \\
\hline Primary & 29 & 8.3 \\
High school & 34 & 9.7 \\
Graduate & 138 & 39.4 \\
Postgraduate & 131 & 37.1 \\
Other & 18 & 5.1 \\
\hline Income & & 28.9 \\
\hline Pk 100000-200000 & 91 & 25 \\
PK 200000-300000 & 89 & 19.4 \\
PK 300000-400000 & 69 & 25.4 \\
PK 400000-above & 101 & \\
\hline & & \\
& Source: Authors Estimation & \\
\hline
\end{tabular}

Table 2 Exploratory Factor Loading

\begin{tabular}{lc}
\hline \multicolumn{1}{c}{ Items } & $\begin{array}{c}\text { Factor } \\
\text { loadings }\end{array}$ \\
\hline Appeal Cronbach's = 0.849 & 0.713 \\
I feel that mobile advertising is good source for timely information & 0.750 \\
Through advertising messages via the MOBILE phone, I receive exclusive information & 0.731 \\
Through advertising messages via the MOBILE phone, I receive exclusive information & .688 \\
Entertainment (Cronbach's a = 0.840) & .744 \\
I feel that receiving mobile advertisement is enjoyable and entertaining & .758 \\
To me it is amusing to receive mobile advertising. & .658 \\
I feel that receiving mobile advertisement is pleasant & .761 \\
I enjoy reading different advertising for the sake of comparison & .742 \\
The advertising messages customized to my profile are fun. & .761 \\
I find advertising messages via the mobile phone exciting & .821 \\
Irritation (Cronbach's a = 0.831) & .798 \\
Mobile marketing does not fit with my shopping style & \\
I feel that mobile advertising is irritating & \\
Content in mobile advertising is often annoying. &
\end{tabular}




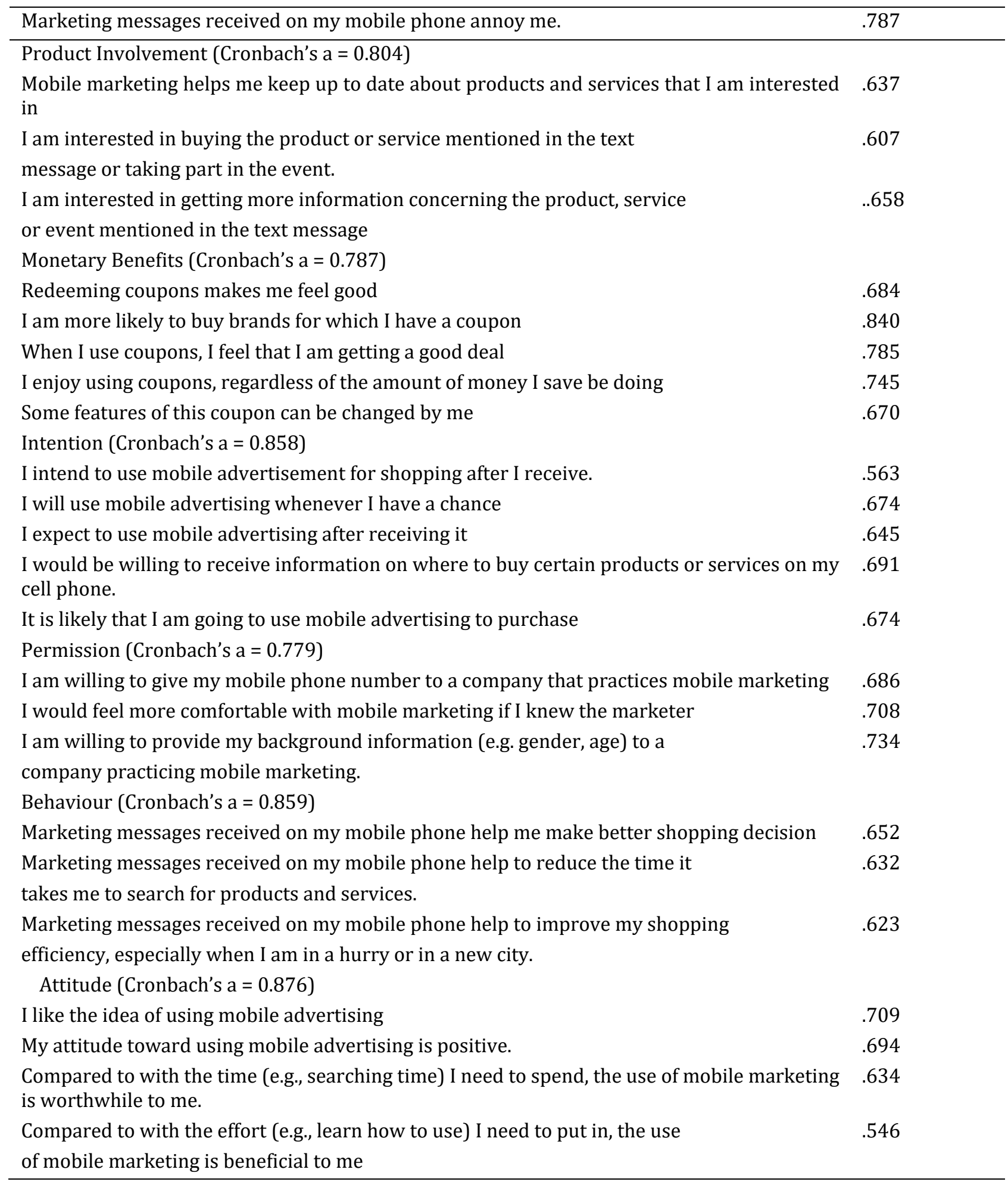

\subsection{Correlation analysis}

Correlation analysis was done in order to study the relationship between the factors affecting consumer attitude towards mobile advertisement. Table 4 represents the overall values. The findings indicate that product involvement, appeal and entertainment have positive correlation with attitude. Only irritation is found to be negatively correlated with attitude towards SMS advertising. 
Table 3 Reliability and confirmatory factor loading

\begin{tabular}{|c|c|c|c|}
\hline Constructs & Items & $\begin{array}{l}\text { Standardized } \\
\text { Loadings }\end{array}$ & $\begin{array}{l}\text { Composite } \\
\text { Reliability }\end{array}$ \\
\hline \multirow[t]{6}{*}{ Entertainment } & Ent 1 & 0.65 & 0.712 \\
\hline & Ent 2 & 0.72 & \\
\hline & Ent 3 & 0.70 & \\
\hline & Ent 4 & 0.55 & \\
\hline & Ent 5 & 0.52 & \\
\hline & Ent 6 & 0.56 & \\
\hline \multirow[t]{3}{*}{ Appeal } & App 1 & 0.55 & 0.860 \\
\hline & App 2 & 0.75 & \\
\hline & App 3 & 0.55 & \\
\hline \multirow[t]{4}{*}{ Irritation } & Irr 1 & 0.50 & 0.890 \\
\hline & Irr 2 & 0.72 & \\
\hline & Irr 3 & 0.60 & \\
\hline & Irr 4 & 0.35 & \\
\hline \multirow{3}{*}{$\begin{array}{l}\text { Product } \\
\text { Involvement }\end{array}$} & PI 1 & 0.52 & 0.710 \\
\hline & PI 2 & 0.61 & \\
\hline & PI 3 & 0.60 & \\
\hline \multirow{4}{*}{$\begin{array}{l}\text { Attitude towards } \\
\text { Mobile Advertising }\end{array}$} & Atma 1 & 0.65 & 0.720 \\
\hline & Atma 2 & 0.65 & \\
\hline & Atma 3 & 0.69 & \\
\hline & Atma 4 & 0.54 & \\
\hline \multirow[t]{5}{*}{ Intention } & Int 1 & 0.47 & 0.700 \\
\hline & Int 2 & 0.61 & \\
\hline & Int 3 & 0.60 & \\
\hline & Int 4 & 0.50 & \\
\hline & Int 5 & 0.61 & \\
\hline \multirow{3}{*}{$\begin{array}{l}\text { Consumer } \\
\text { Behaviour }\end{array}$} & CB 1 & 0.69 & 0.752 \\
\hline & CB 2 & 0.76 & \\
\hline & CB 3 & 0.63 & \\
\hline
\end{tabular}

\subsection{Model Fit}

To analyze the simultaneous effects of the variables included in the final construct, the model was further studied by structural equation modeling. From the results of various indices, model showed good fitness. The value of Chi- Square (CMIN/DF) was (2.23) which is between the acceptable range of 3:1(Kline, 2011) and CMIN is (754.672), df (338) and 
Probability level is (0.000). While Goodness of Fit Index(GFI) is (0.863) and possible good range of GFI is 0-1, however high values show better fit, previously values greater than 0.90 were considered good (Hair, Black, Babin, \& Anderson, 2010). Trucker Lewis

Index (TLI) is found to be (0.922) which also lies in the acceptable range of 0 to 1 (Byrne, 2013; Arif, Afshan, \& Sharif, 2016) for better model fitness. Root Mean Square Error of Approximation is (.059) which is less than 0.07 shows good fit (Byrne, 2013). The result showed that the overall model was a good fit at 95\% level of confidence. Table 5 represents the overall values of model fitness.

Table 4 Correlation analysis

\begin{tabular}{|c|c|c|c|c|c|}
\hline & 1 & 2 & 3 & 4 & 5 \\
\hline $\begin{array}{l}\text { Attitude } \\
\text { towards SMS } \\
\text { advertisement }\end{array}$ & 1 & & & & \\
\hline Entertainment & $.581^{* *}$ & 1 & & & \\
\hline Irritation & $-.310^{* *}$ & $-.340^{* *}$ & 1 & & \\
\hline $\begin{array}{l}\text { Product } \\
\text { involvement }\end{array}$ & $.647^{* *}$ & $.690 * *$ & $-.263^{* *}$ & 1 & \\
\hline Appeal & $.641^{* *}$ & $.570^{* *}$ & -.292 & $0.604^{* *}$ & 1 \\
\hline Mean & 3.26 & 2.907 & 3.22 & 3.16 & 3.15 \\
\hline Std Deviation & 0.90 & 0.93 & 0.89 & 0.89 & 0.96 \\
\hline
\end{tabular}

Table 5 Model Fit

\begin{tabular}{|c|c|c|}
\hline Model & Recommended Model Fit & Model value \\
\hline x2 (chi-square) & & 754.672 \\
\hline df (degrees of freedom) & & 338 \\
\hline Chi-square/df (x2/df) & $<3 a$ & 2.23 \\
\hline GFI (Goodness of Fit Index & $>0.9 \mathrm{a}$ & 0.91 \\
\hline $\begin{array}{l}\text { RMSEA (Root Mean Square Error of } \\
\text { Approximation) }\end{array}$ & $<0.08 b$ & 0.059 \\
\hline $\begin{array}{l}\text { TLI (Tucker-Lewis index or NNFI? non-normed } \\
\text { fit index) }\end{array}$ & $>0.90 \mathrm{a}$ & 0.922 \\
\hline CFI (Comparative Fit Index) & $>0.90 \mathrm{a}$ & 0.930 \\
\hline IFI (Incremental Fit Index) & $>0.90 \mathrm{a}$ & 0.931 \\
\hline PCFI (Parsimony Comparative of Fit Index) & $>.50$ & 0.832 \\
\hline PNFI (Parsimony Normed Fit Index & $>.50$ & 0.788 \\
\hline
\end{tabular}

\subsection{Path analysis}

Table 6 shows the relationship between the constructs. According to the result appeal, entertainment and product involvement have a positive and significant impact on attitude towards SMS advertisement, while only irritation has an insignificant negative impact on the attitude towards SMS advertisement. Consumer attitude towards SMS advertisement also have significant impact on consumers' intentions to receive SMS advertisement and consumers' intentions affect the behavior after receiving the SMS advertisement. Hence H7 and H8 are supported along with H1,H2, and $\mathrm{H} 4$ for appeal, entertainment and product involvement. 
Table 6 Hypothesis Testing

\begin{tabular}{llllll}
\hline Path & B & S. E & C.R & P & Result \\
\hline Attitude $\leftarrow$ Entertainment & 0.166 & 0.071 & 2.331 & 0.020 & Supported \\
Attitude $\leftarrow$ Appeal & 0.277 & 0.067 & 4.144 & 0.000 & Supported \\
Attitude $\leftarrow$ Irritation & -.064 & 0.042 & -1.514 & 0.130 & Not Supported \\
Attitude $\leftarrow$ Product Involvement & 0.477 & 0.087 & 5.503 & 0.000 & Supported \\
Intention $\leftarrow$ Attitude & 0.682 & 0.057 & 11.981 & 0.000 & Supported \\
Behaviour $\leftarrow$ Intention & 1.023 & 0.087 & 11.809 & 0.000 & Supported \\
\hline
\end{tabular}

Source: Authors' Estimation

\section{Consumer attitude and permission}

For the analysing the impact of permission on consumer attitude towards SMS Advertising, simple linear regression analysis was performed. According to the findings, permission-based model has a significant on consumer attitude towards SMS advertising and is found significant $(\mathrm{t}=12.563, \mathrm{p}=0.000)$. Table 7 represents the overall values.

Table 7 Consumer Attitude and Permission

\begin{tabular}{llllll}
\hline Factor & Beta & t-stat & Prob & Adj.R Square & F-stats \\
\hline Permission & 0.559 & 12.563 & 0.000 & 0.310 & 157.829 \\
\hline \multicolumn{7}{r}{ Note: Significant at the 0.05 Source: Authors' Estimation }
\end{tabular}

\section{Intention and monetary benefits}

In order to study the relationship, monetary benefits have been regressed on intention to receive SMS advertisement. According to the findings, it is established that monetary benefits have significant $(t=11.659, p=0.000)$ and positive impact on consumers 'intention to receive SMS advertisement. Table 8 represents the values of the result found after the regression analysis.

Table 8 Intention to receive SMS Advertisement

\begin{tabular}{llllll}
\hline Factor & Beta & t-stat & Prob & R-Square & F-stat \\
\hline $\begin{array}{l}\text { Monetary } \\
\text { Benefits }\end{array}$ & 0.511 & 11.659 & 0.000 & 0.279 & 135.928 \\
\hline
\end{tabular}

Note =Significant at 0.05, Authors Estimation

\section{Conclusion}

Empirical analysis showed that there is positive attitude of consumers towards SMS advertising because of the factors like entertainment, product involvement and appeal. Product involvement has been found to be the most important factor to inculcate positive attitude towards SMS advertisement followed by appeal and entertainment. The finding related to the factor appeal are consistent with many of the previous researchers ,which reassures that appeal is the most significant factor having a direct impact on consumer attitude and purchase intention. Only irritation is found to be negatively insignificant and this finding is also similar with the previous studies. Insignificant nature of irritation showed that consumers do not get annoyed from SMS advertising and this is quite possible that they get involved in the advertisement ,if companies make more appealing and entertaining advertisement .Negative sign of irritation represents that if the consumer get annoyed or irritated positive attitudes will be low towards SMS advertising and vice versa. The attitudes of consumer become favorable by taking prior permission for them. This confirmed prior permission should be made an obligatory factor in future SMS advertisement. These result are similar with the findings of many previous researchers who have found permission to be an essential factor for achieving positive results in 
advertising via mobile phones. A positive relation has also been found between attitude and intention to receive SMS advertisement. Intention is affected by monetary benefits. People like to receive benefits-based SMS advertisements. Finally, it was also found that intention has a significant impact on the behavior of the respondents. These results are consider with RRA model and literature discussed.

\section{Compliance with ethical standards}

\section{Acknowledgments}

Special thanks to Ghulam Murtaza PhD scholar of Environmental Sciences.

\section{Disclosure of conflict of interest}

I have no conflict of interest.

\section{References}

[1] Ajzen I. (1991). The theory of planned behavior. Organizational behavior and human decision processes, 50 (2), 179-211.

[2] Andersson A and Nilsson J. (2000). Wireless advertising effectiveness: Evaluation of an SMS advertising trial, master's thesis in marketing, Stockholm school of economics Anderson. Retrieved July 29.

[3] Arif I, Afshan S and Sharif A. (2016). Resistance to Adopt Mobile Banking in a Developing Country: Evidence from Modied TAM Model. Journal of Finance \& Economics Research, 1 (1), 23-38.

[4] Arif I and Aslam W. (2014). Students' dependence on smart phone and its effect on purchase behavior. Munich Personal RePEc Archive, 58919, 1-11.

[5] Bagozzi RP and Yi Y. (1988). On the evaluation of structural equation model. Journal of Academy of Marketing Science, 16 (1), 74-94.

[6] Baker WE and Lutz RJ. (2000). An empirical test of an updated relevance-accessibility model of advertising effectiveness. Journal of Advertising, 1-14.

[7] Barnes SJ and Scornavacca E. (2004). Mobile marketing: the role of permission and acceptance. International Journal of Mobile Communications, 2 (2), 128-139.

[8] Barwise P and Strong, C. (2002). Permission-based mobile advertising. Journal of inter- active Marketing, 16 (1), 14-24.

[9] Bauer HH, Barnes SJ, Reichardt T and Neumann MM. (2005). Driving con- summer acceptance of mobile marketing: a theoretical framework and empirical study. Journal of electronic commerce research, 6 (3), 181192.

[10] Browne MW and Cudeck R. (1993). Alternative ways of assessing model fit, sage publications. Sage Publications, Newbury Park, CA.

[11] Bruner II GC and Kumar A. (2007). Gadget lovers. Journal of the Academy of Marketing Science, 35 (3), 329-339.

[12] Byrne BM. (2013). Structural equation modeling with amos: Basic concepts, applications, and programming. Routledge.

[13] Carroll A, Barnes SJ and Scornavacca E. (2005). Consumers perceptions and attitudes towards SMS mobile marketing in New Zealand. In Mobile business. icmb. international conference on 434-440.

[14] Carroll A, Barnes SJ, Scornavacca E and Fletcher K. (2007). Consumer perceptions and attitudes towards SMS advertising: recent evidence from New Zealand. Interna- tional Journal of Advertising, 26 (1), 79-98.

[15] Chen S-FS, Monroe KB and Lo1u Y-C. (1998). The effects of framing price promotion messages on consumers' perceptions and purchase intentions. Journal of retailing, 74 (3), 353-372.

[16] Chowdhury HK, Parvin N, Weitenberner C and Becker M. (2010). Consumer attitude toward mobile advertising in an emerging market: An empirical study. Marketing, 12 (2), 206-216. 
[17] Csikszentmihalyi M. (1975). Play and intrinsic rewards. Journal of humanistic psychology. Cuneo. (2004, November). Marketers dial into messaging. advertising age. Advertising Age

[18] Cutitta. (2005). Mobile advertising around the world. presentation materials: preconfer- ence wireless promotional strategies around the world. The annual conference of the American academy of advertising, Houston.

[19] Demarneffe H. (2008). Mobile advertising white paper-how telcos can dominate the advertising industry. Mechelen: The House of Marketing.

[20] Dickinge A, Haghirian P, Murphy J and Scharl A. (2004). An investigation and conceptual model of SMS marketing. In System sciences, 2004. proceedings of the 37th annual hawaii international conference on 10.

[21] Drossos D, Giaglis GM, Lekakos G, Kokkinaki F and Stavraki MG. (2007). Deter- minants of effective SMS advertising: an experimental study. Journal of Interactive Advertising, 7(2), 16-27.

[22] Drossos DA, Giaglis GM, Vlachos PA, Zamani ED and Lekakos G. (2013). Consumer responses to SMS advertising: Antecedents and consequences. International Journal of Electronic Commerce, 18(1), 105-136.

[23] Ducoffe RH. (1996). Advertising value and advertising on the web. Journal of advertising research, 36(5), 21-35.

[24] Edwards P, Roberts I, Clarke M, DiGuiseppi C, Pratap S, Wentz R and Kwan I. (2002). Increasing response rates to postal questionnaires: systematic review. Bmj, 324 (7347), 1183.

[25] Fishbein M and Ajzen I. (1975). Belief, attitude, intention and behavior: An introduction to theory and research.

[26] Fishbein M, Middle Stadt SE and Hitchcock PJ. (1994). Using information to change sexually transmitted diseaserelated behaviors. In Preventing aids. 61- 78. Springer.

[27] Garnter. (2011). Worldwide mobile advertising revenue forecast to reach \$ 3.3 billion in 2011.

[28] Haghirian P, Madlberger M and Tanuskova A. (2005). Increasing advertising value of mobile marketingan empirical study of antecedents. In System sciences, 2005. hicss'05. proceedings of the 38th annual hawaii international conference on $(32 c-32 c)$.

\section{How to cite this article}

Razzaq Abdul and Ashfaq Muhammad. (2019). Behavior and attitude of the mobile phones users towards SMS advertising: A study in an emerging economy. World Journal of Advanced Research and Reviews, 4(1), 25-36. 